\title{
Are sacred caves still safe havens for the endemic bats of Madagascar?
}

\author{
Álvaro Fernández-Llamazares, Adrià López-Baucells, Ricardo Rocha, \\ Santatra F. M. Andriamitandrina, Zo Emmanuel Andriatafika, \\ Daniel Burgas, Eric Marcel Temba, Laura Torrent and Mar Cabeza
}

\begin{abstract}
Despite conservation discourses in Madagascar increasingly emphasizing the role of customary institutions for wildlife management, we know relatively little about their effectiveness. Here, we used semi-structured interviews with 54 adults in eight villages to investigate whether sacred caves and taboos offer conservation benefits for cave-dwelling bats in and around Tsimanampetsotsa National Park, south-west Madagascar. Although some caves were described as sites of spiritual significance for the local communities, most interviewees (c. 76\%) did not recognize their present-day sacred status. Similarly, only $22 \%$ of the interviewees recognized taboos inhibiting bat hunting and consumption. Legal protection of bats and caves through protected areas was often more widely acknowledged than customary regulations, although up to $30 \%$ of the interviewees reported consumption of bats within their communities. Guano extraction was often tolerated in sacred caves in exchange for economic compensation. This may benefit bat conservation by creating incentives for bat protection, although extraction is often performed through destructive and exploitative practices with little benefit for local communities. In view of these results our study questions the extent to which sacred sites, taboos and protected areas offer protection for bats in Madagascar. These results support previous studies documenting the erosion of
\end{abstract}

Álvaro Fernández-Llamazares (Corresponding author), Laura Torrent, Mar CABEza Metapopulation Research Centre, Department of Biosciences, University of Helsinki, P.O. Box 65, Viikinkaari 1, FI-00014, Helsinki, Finland. E-mail alvaro.fernandez-llamazares@helsinki.fi

Adrià LÓPEZ-BAuCELls ${ }^{\star} \dagger$ Granollers Museum of Natural Sciences, Granollers, Catalonia, Spain

Ricardo Rocha ${ }^{*}$ Centre for Ecology, Evolution and Environmental Changes, University of Lisbon, Lisbon, Portugal

Santatra F. M. Andriamitandrina*, Eric Marcel Temba* Mention Zoology and Animal Biodiversity, University of Antananarivo, Antananarivo, Madagascar

Zo Emmanuel Andriatafika* Institute of Science and Technics of the Environment, University of Fianarantsoa, Fianarantsoa, Madagascar

Daniel BuRgas ${ }^{*} \$$ Department of Biological and Environmental Sciences, University of Jyväskylä, Jyväskylä, Finland

${ }^{*}$ Also at: Metapopulation Research Centre, University of Helsinki, Finland $\dagger$ Also at: Centre for Ecology, Evolution and Environmental Changes, University of Lisbon, Portugal

¥Also at: Conservation Science Group, Department of Zoology, University of Cambridge, United Kingdom

§Also at: Department of Forest Sciences, University of Helsinki, Finland

Received 28 July 2017. Revision requested 17 October 2017.

Accepted 25 October 2017. First published online 14 February 2018. customary institutions in Madagascar, including the loss of the spiritual values underpinning sacred sites. Given that many Malagasy bats are cave-dwelling species and that most depend on the customary protection of these sites, it is important to obtain a better understanding of the complex interactions between spiritual practices, taboos and protected areas in sustaining bat diversity.

Keywords Bats, culture, customs, $f a d y$, Madagascar, sacred natural sites, spiritual values, Tsimanampetsotsa National Park

The supplementary material for this article is available at https://doi.org/10.1017/So030605317001648

The sacred status that many human societies have con1 ferred to caves has generally discouraged the disturbance of cave-dwelling species living within them (Sponsel \& Natadecha-Sponsel, 2004; Sponsel, 2015). This form of customary protection has thus contributed to the conservation of bat diversity (Robinson \& Smith, 1997; Metcalfe et al., 2010; Furey \& Racey, 2016). The protection provided by sacred caves is particularly important on tropical islands, on which endemic species are common (Conenna et al., 2017). Madagascar has a high level of bat endemicity, with at least 32 of its c. 44 species (73\%) being endemic (Cardiff \& Jenkins, 2016). Cave systems in the western part of the island are particularly important in this respect (Goodman et al., 2005; Cardiff, 2006).

The inherent spiritual respect that caves evoke in many Malagasy cultural traditions (Hobbs, 2001) has conferred protection on cave-dwelling bats. As a result, the recognition of sacred caves is important for bat conservation (Schachenmann, 2006). However, numerous endemic cave-dwelling bat species, such as the Vulnerable Eidolon dupreanum, Near Threatened Roussetus madagascariensis and Near Threatened Hipposideros commersoni, are increasingly under threat, probably as a result of hunting pressure and other anthropogenic disturbances (Jenkins et al., 2007; Cardiff et al., 2009; Andrianaivoarivelo et al., 2012).

We know relatively little about the effectiveness of sacred caves in conserving bat diversity. Some authors have shown that numerous bat species of conservation concern can roost safely in sacred caves (Robinson \& Smith, 1997; Metcalfe 


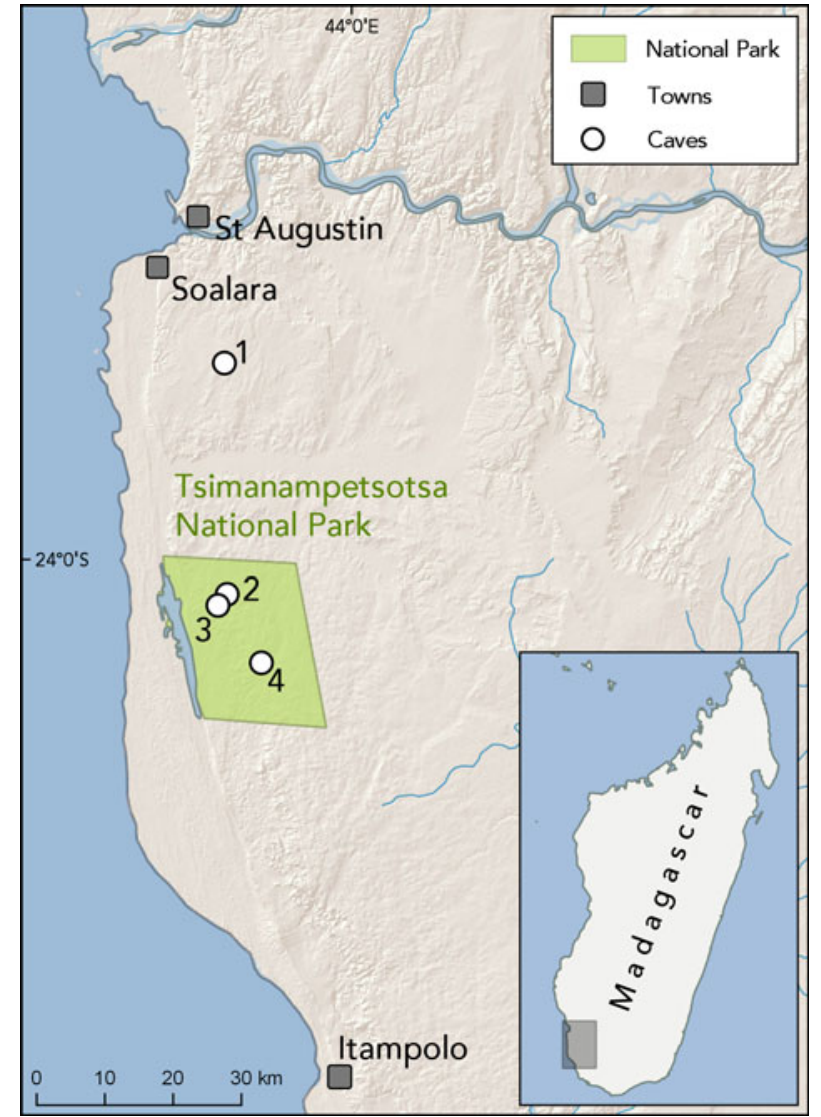

FIG. 1 Map of the study area with the four sacred caves surveyed (white circles) and the main towns in the area (dark squares). Specific names and locations of the sacred caves are not provided in order to protect the bat colonies. Specific names and locations of the villages where interviews were conducted are not provided in order to protect the anonymity of the interviewees.

et al., 2010), whereas others suggest that the cultural values underpinning these sites are eroding (Golden \& Comaroff, 2015a; Kingston, 2015). It is also unclear whether these island-like refuges can effectively protect mobile species that forage beyond the boundaries of sacred sites. Thus, the effectiveness of sacred caves in conserving bats cannot be taken for granted if spiritual values become eroded.

With empirical evidence on this matter still largely lacking, we set to explore local attitudes towards bats and sacred caves among two ethnic groups (Tanalana and Vezo) inhabiting the karstic area in and around Tsimanampetsotsa National Park in south-western Madagascar (Fig. 1). The Vezo live by the sea and are predominantly fishers; the Tanalana live inland and are mostly agro-pastoralists. Some sacred caves in this area are within the National Park, whereas others are governed only through customary institutions. Customary governance of sacred caves is articulated through an intricate combination of community rules, cultural taboos $(f a d y)$, and ancestral customs (Tahirindraza, 2015; Fritz-Vietta et al., 2017).

In this complex landscape of governance diversity we conducted semi-structured interviews with 54 adults in eight villages, to gain insights into cultural values, local uses and knowledge of bats, and the local management of sacred caves. Fieldwork took place in November 2016, adhering to the Code of Ethics of the International Society of Ethnobiology. Free, prior and informed consent was obtained from all individuals participating in this study, as well as from the relevant political organizations in the area. For details of the interview protocols, sample composition and construction of quantitative variables see Supplementary Material 1 and Supplementary Tables 1-2. To contextualize our social data, we also carried out mist-netting surveys to gather information on bat species in four sacred caves (Supplementary Table 3).

The sacred caves of Tsimanampetsotsa were often described by interviewees as spaces at the interface between the natural and supernatural worlds, being a focus of spiritual devotion. Some interviewees believed in the presence of spirits in the depths of the caves. Evidence of traditional uses such as funerary ceremonies or ritual offerings were found in the entrance of two of the four caves surveyed (Plate 1). Bats were also believed to roam at the junction between the physical and spiritual realms, protecting treasures out of human reach. People usually reported respecting the roosting bats, by avoiding entering the caves, mainly because they feared being harmed by spirits. These caves are home to at least six bat species, including the threatened Madagascar fruit bat Eidolon dupreanum. They harbour some of the largest maternity colonies of molossid bats within the region, with hundreds to thousands of individuals roosting together. These roosts are used at least during the breeding season, given that pregnant and lactating females were detected (Supplementary Table 3).

Malagasy people not only have spiritual connections with sacred sites but also an extensive system of species- and placespecific taboos, which shape social behaviour and cultural practices around wildlife. Many of these taboos relate to consumptive uses of animals, potentially offering protection to a great number of species (Jones et al., 2008). In particular, bat taboos are common among many Malagasy ethnic groups (Rahaingodrahety et al., 2008; Golden \& Comaroff, 2015b). This is also true in Tsimanampetsotsa, where we found that $22 \%$ of the interviewees recognized bat-related taboos inhibiting bat hunting and consumption. The public acceptance of bat-related taboos was slightly higher than the recognition of the sacredness of caves (15\%; Fig. 2a). Both site- and speciesrelated taboos were reported more often in Tanalana communities $(63 \%)$ than among the Vezo (17\%), although there was some variation between villages and age groups in both cases. Such heterogeneity in the knowledge of, and/or adherence to, bat taboos has been documented elsewhere in Madagascar (Golden \& Comaroff, 2015a).

The existence of legal regulations conveyed through the National Park was often more widely acknowledged (30\%) than the role of customary institutions (sacred sites and 

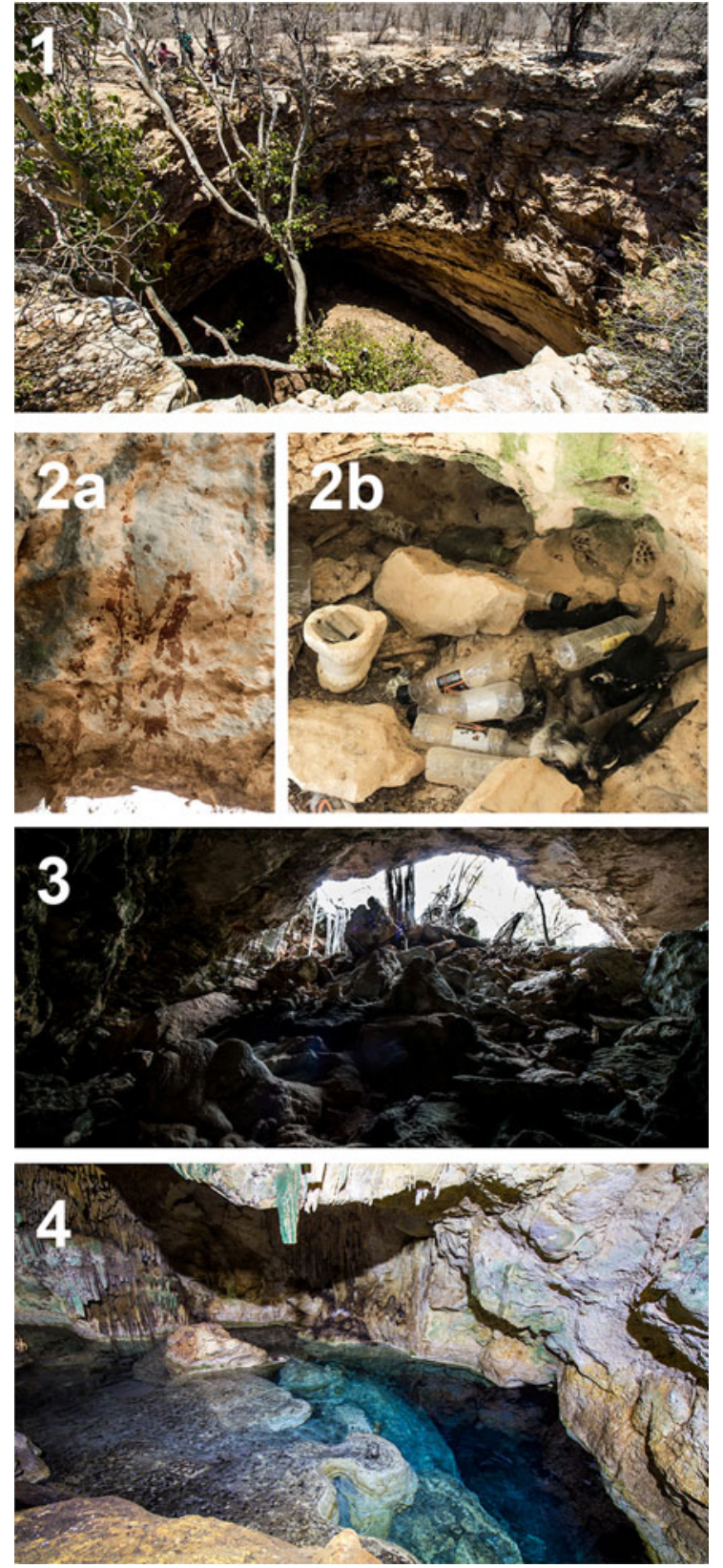

Plate 1 Entrances of the four caves surveyed in this study. Numbers correspond to the locations in Fig. 1. 2a-b show some of the ritual offerings found in one of the sacred caves: blood of a sacrificed black goat and bottles of locally brewed alcohol (e.g. toaka gasy) for the spirits.

taboos; Fig. 2a). Nevertheless, the lack of knowledge of conservation policy and related legal regulations was high, with $39 \%$ of respondents expressing confusion about what was protected, where and, most notably, by whom. Although many local people recognized the functions of the National Park in conserving bats, others complained about recent changes in regulations limiting their access to sacred caves. Park management rules allow certain cultural uses (e.g. sacred rituals), but many informants expressed concerns about having lost cultural connections to spiritual (a) Recognition of protection

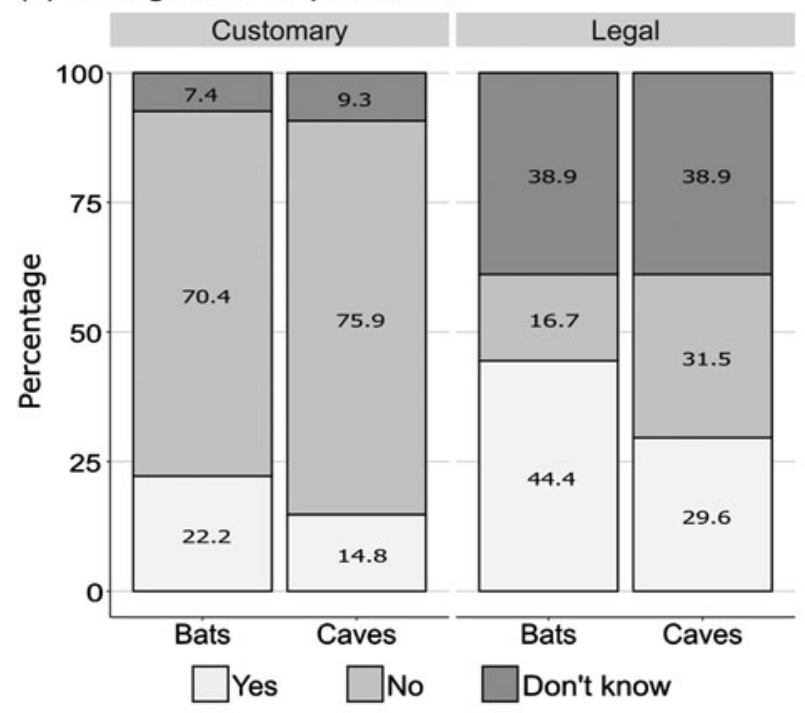

(b) Reported use of bats

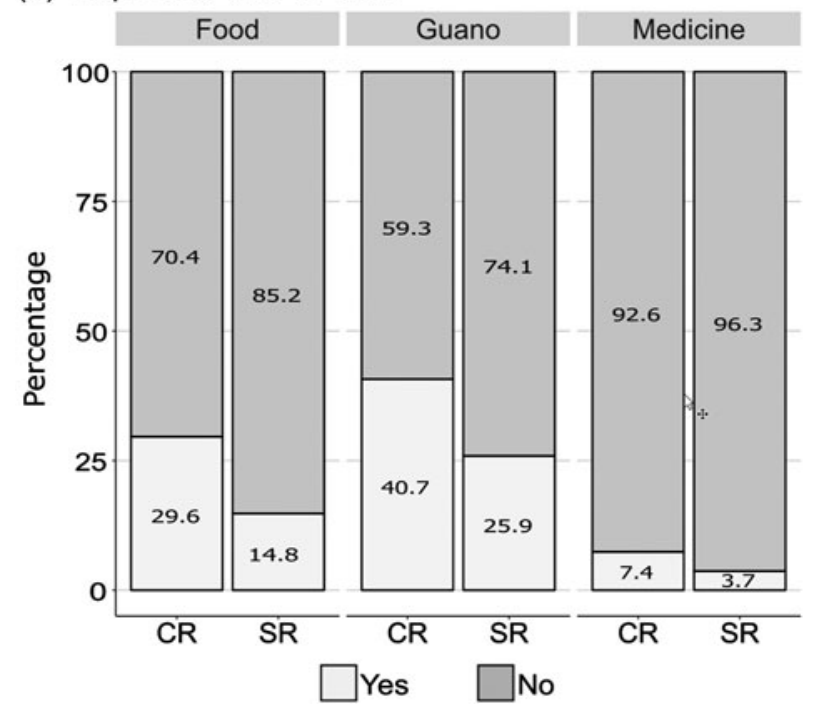

FIG. 2 (a) Percentages of self-reported recognition of the customary and legal instruments protecting bats and caves. (b) Percentages of community-reported (CR) and self-reported (SR) use of bats for food, guano and medicinal purposes.

sites inside the Park, because access to these sites now requires the payment of a Park entrance fee. This could explain why customary management of sacred caves was generally undervalued.

We also found widespread evidence of people using sacred caves for bat hunting. Up to $30 \%$ of the people interviewed reported bat consumption in their communities (Fig. 2b). Hunting of bat species, such as E. dupreanum or Mormopterus jugularis, was often performed with nets, sticks and stones in sacred caves (both within and outside the National Park). Reports of hunting within the park were, however, more anecdotal, taking place mostly in times of famine. For instance, in 2007, during a period of 
acute drought and consequent food insecurity, a large number of bats were killed with fire in a sacred cave within the National Park. According to several local informants, these bats 'fed 200 people for 2 months'. In general, people reported that hunting in caves maximized the probabilities of a successful hunt, given that bats are more easily accessible when they are roosting. For example, a Tanalana informant stated 'People do not catch bats in the village; they prefer to catch them in the cave, when they sleep. They throw stones to catch them, and eat them'.

Bat hunting was also linked to children's games in school buildings and caves, a phenomenon reported by $26 \%$ of all interviewees. Several bat species roost in school buildings in Madagascar (López-Baucells et al., 2017), which facilitates encounters with children. They often capture bats during playtime in school, tying them with ropes and singing a well-known tune (Kinnakina baka nihina), alluding to bats being killed to stop their snoring. Such games usually end with the death of the bat. We also found anecdotal reports of medicinal uses of bats, mostly in the form of a 'bat oil medicine' made by decanting the oil obtained from boiling a bat in water. According to the interviewees, this oil is traditionally applied on the scalp to aid hair growth, or to cure coughs. Similar findings have been reported from Andringitra National Park (Jenkins \& Racey, 2008).

Although bat consumption is common across Madagascar (Jenkins \& Racey, 2008), no evidence of bat trade was found in the area. However, guano collection for commercial purposes was explicitly mentioned as an important source of income. Guano extraction is often tolerated in certain sacred sites, although it was always reported as occurring outside the National Park. Extraction is carried out in exchange for economic compensation (e.g. job opportunities or infrastructure development) on the condition that the companies perform certain rituals (e.g. spilling a few drops of alcohol by the entrance) and agree not to touch certain venerated sites (Buliga, 2010). The growing presence of guano companies in the area is of concern, given that human disturbance inside the caves often leads to displacement of bat populations (Cardiff \& Jenkins, 2016). In addition, companies usually modify the geological structure of caves to facilitate guano extraction, altering the microclimate required for bat roosting (IUCN SSC, 2014). Although bats were present in some caves following guano harvesting, without prior knowledge of these populations the effects of harvesting are unclear.

The economic benefits derived from guano collection could motivate people to conserve bats and their habitats, as suggested by a Tanalana man stating 'Now the parents tell the kids to protect the caves. In 2014 there was a company who came and bought all the guano'. In fact, most of the value that our informants attributed to bats can be directly traced to guano-related income ( $41 \%$ of all respondents), whereas relational values such as aesthetic appreciation or cultural identity (15\%) were less relevant.
This suggests that harvesting guano could, under certain circumstances, benefit bat conservation, although this is not currently allowed within the National Park. However, caution is required, given that guano extraction is often performed through destructive and exploitative practices.

None of the interviewees who had extracted guano reported any sacred values or taboos related to caves. Similarly, none of the people who recognized caves as sacred reported extracting guano. Given that mentioning a taboo does not necessarily mean respecting it (Golden \& Comaroff, 2015a), these results cannot be taken as direct proxies for taboo adherence. They do, however, open avenues for further research on the role of cultural values in bat conservation.

Although sacred sites and taboos exist for social and cultural reasons other than biodiversity conservation (Rutte, 2011), their role in wildlife management is increasingly emphasized in conservation discourses in Madagascar (Schachenmann, 2006; Rahaingodrahety et al., 2008). However, our study questions the current effectiveness of sacred sites and taboos, at least in conserving bats, and confirms the pervasive erosion of customary institutions in Madagascar (Jenkins et al., 2011; Golden \& Comaroff, 2015a). If the spiritual values associated with bats and caves are lost, the effectiveness of these sacred sites for protecting bat populations will be in jeopardy.

Given that cave-dwelling bat species tend to form the largest colonies (McCracken, 1986), protection of such roosts is paramount for bat conservation. Cave-dwelling bats are particularly vulnerable to hunting pressure because capturing large numbers is facilitated by the enclosed space (Jenkins et al., 2007). This is particularly problematic on islands, where most bat species are endemic and have restricted ranges (Conenna et al., 2017). Because both bat-specific and cave-specific taboos now have a relatively low prevalence among communities in Madagascar, probably because of rapid cultural changes, the extent to which they offer effective protection for bats is questionable. It is thus essential to better understand the complex interactions between sacred sites, taboos and protected areas in preserving bat diversity.

\section{Acknowledgements}

Research permits were issued by the Ministry of the Environment, Ecology and Forests of Madagascar (Agreement Nr. 275/16/MEEF/SG/DGF/DSAP/SCB.Re) and Madagascar National Parks. The research leading to these results has received funding from the Academy of Finland (grant agreement nrs. 311176 and 292765). We thank the Tanalana and Vezo people who have generously opened the doors of their houses and their sacred worlds for us, Madagascar National Parks for their support, Association SAME for their help during fieldwork and translation services, and A. Pyhälä and V. Reyes-García for insightful comments on a previous version of the interview protocol. 


\section{Author contributions}

AFLL, ALB, RR and MC designed the study. All authors collected data. DB analysed the data. AFLL, ALB, DB and RR prepared the figures and tables. AFLL and ALB led the writing, with contributions from all co-authors. MC supervised the project through all its phases.

\section{References}

Andrianaivoarivelo, R.A., Andriafidison, D., Rahaingonirina, C., Raharimbola, S., Rakotoarivelo, A., Ramilijaona, O. et al. (2012) A conservation assessment of Rousettus madagascariensis (G. Grandidier, 1928, Pteropodidae) roosts in eastern Madagascar. Madagascar Conservation \& Development, 6, 78-82.

Buliga, C. (2010) Guano Exploitation in Madagascar. Independent Study Project (ISP) Collection. Http://digitalcollections.sit.edu/isp_ collection/904 [accessed 18 July 2017].

CARDIFF, S.G. (2006) Bat cave selection and conservation in Ankarana, northern Madagascar. MSc thesis, Columbia University, New York, USA.

Cardiff, S.G. \& Jenkins, R.K.B. (2016) The bats of Madagascar: a conservation challenge. Lessons in Conservation, 6, 80-108.

Cardiff, S.G., Ratrimomanarivo, F.H., Rembert, G. \& Goodman, S.M. (2009) Hunting, disturbance and roost persistence of bats in caves at Ankarana, northern Madagascar. African Journal of Ecology, 47, 640-649.

Conenna, I., Rocha, R., Russo, D. \& Cabeza, M. (2017) Insular bats and research effort: a review of global patterns and priorities. Mammal Review, 47, 169-182.

Fritz-Vietta, N.V.M., Tahirindraza, H.S. \& Stoll-Kleemann, S. (2017) Local people's knowledge with regard to land use activities in southwest Madagascar - Conceptual insights for sustainable land management. Journal of Environmental Management, 199, 126-138.

Furey, N.M. \& RACEY, P.A. (2016) Conservation ecology of cave bats. In Bats in the Anthropocene: Conservation of Bats in a Changing World (eds C.C. Voigt \& T. Kingston), pp. 463-50o. Springer, Cham, Switzerland.

Golden, C.D. \& Comaroff, J. (2015a) Effects of social change on wildlife consumption taboos in northeastern Madagascar. Ecology and Society, 20, 41.

Golden, C.D. \& Comaroff, J. (2015b) The human health and conservation relevance of food taboos in northeastern Madagascar Ecology and Society, 20, 42.

Goodman, S.M., Andriafidison, D., Andrianaivoarivelo, R., Cardiff, S.G., Ifticene, E., Jenkins, R.K.B. et al. (2005) The distribution and conservation of bats in the dry regions of Madagascar. Animal Conservation, 8, 153-165.

Новвs, J.J. (2001) People and caves in Madagascar. Focus on Geography, 46, 1-7.

IUCN SSC (2014) IUCN SSC Guidelines for Minimizing the Negative Impact to Bats and Other Cave Organisms from Guano Harvesting. Ver. 1.o. IUCN SSC, Gland, Switzerland.

Jenkins, R. \& Racey, P.A. (2008) Bats as bushmeat in Madagascar. Madagascar Conservation \& Development, 3, 22-30.

Jenkins, R.K.B., Racey, P.A., Andriafidison, D., Razafindrakoto, N., Razafimahatratra, E., Rabearivelo, A. et al. (2007) Not rare, but threatened: the endemic Madagascar flying fox Pteropus rufus in a fragmented landscape. Oryx, 41, 263-271.

Jenkins, R.K.B., Keane, A., Rakotoarivelo, A.R. RaKotomboavoniy, V., RandrianandRianina, F.H.,
RaZafimanahaKa, H.J. et al. (2011) Analysis of patterns of Bushmeat consumption reveals extensive exploitation of protected species in eastern Madagascar. PLoS ONE, 6, e27570.

Jones, J.P.G., Andriamarovololona, M.M. \& Hockley, N. (2008) The importance of taboos and social norms to conservation in Madagascar. Conservation Biology, 22, 976-986.

Kingston, T. (2015) Cute, creepy, or crispy - how values, attitudes and norms shape behavior toward bats. In Bats in the Anthropocene: Conservation of Bats in a Changing World (eds C.C. Voigt \& T. Kingston), pp. 571-595. Springer, Cham, Switzerland.

López-Baucells, A., Rocha, R., Andriatafika, Z., Tojosoa, T. Kemp, J., Forbes, K. \& CabeZA, M. (2017) Roost selection by synanthropic bats in rural Madagascar: what makes non-traditional structures so tempting? Hystrix, 28, http://dx.doi.org/10.4404/ hystrix-28.1-12046.

MCCRACKen, G.F. (1986) Why are we losing our Mexican free-tailed bats? Bats, 3, 1-2.

Metcalfe, K., Ffrench-Constant, R. \& Gordon, I. (2010) Sacred sites as hotspots for biodiversity: the Three Sisters Cave complex in coastal Kenya. Oryx, 44, 118-123.

Rahaingodrahety, V.N., Andriafidison, D., Ratsimbazafy, J.H., Racey, P.A. \& Jenkins, R.K.B. (2008) Three flying fox (Pteropodidae: Pteropus rufus) roosts, three conservation challenges in southeastern Madagascar. Madagascar Conservation \& Development, 3, 17-21.

Robinson, M.F. \& Smith, A.L. (1997) Chiroptera from Loei Province, north-east Thailand. Natural History Bulletin of the Siam Society, 45, $1-16$.

Rutte, C. (2011) The sacred commons: Conflicts and solutions of resource management in sacred natural sites. Biological Conservation, 144, 2387-2394.

Schachenmann, P. (2006) Spiritual values in Madagascar. Mountain Research and Development, 26, 323-327.

SPONSEL, L.E. (2015) Sacred caves of the world: illuminating the darkness. In The Changing World Religion Map (ed. S.D. Brunn), pp. 503-522. Springer, Dordrecht, The Netherlands.

Sponsel, L.E. \& Natadecha-Sponsel, P. (2004) Illuminating darkness: the monk-cave-bat-ecosystem complex in Thailand. In This Sacred Earth: Religion, Nature, Environment (ed. R.S. Gottlieb), pp. 124-144. Psychology Press, London, UK.

TAHIRINDRAZA, H.S. (2015) Taboos as a key element for nature conservation in the Tanalana territory South-Western Madagascar. Report of the Sustainable Land Management Project. University of Toliara, Madagascar. Http://www.sulama.de/files/products/WP Product1_Tabous_eng.pdf [accessed 18 July 2017].

\section{Biographical sketches}

All authors are members of the Global Change and Conservation research group (GCC; http://gcc.it.helsinki.fi) at the Department of Biosciences, University of Helsinki, Finland. GCC is known for its interdisciplinary cross-cutting conservation research, integrating social and ecological data at multiple scales. Álvaro Fernandez-Llamazares is an ethnoecologist interested in biocultural approaches to conservation. Adrià López-Baucells, Ricardo Rocha and Laura TORRENT work on bat ecology and conservation. SANTATRA F.M. Andriamitandrina, Zo Emmanuel Andriatafika and Eric MARCEL TEMB A conduct research on the human dimensions of conservation in Madagascar, with emphasis on bird communities. DANIEL BURGAS is a conservation ecologist with experience in designing collection of field data and interest in optimal ecological sampling. MAR CABEZA is the leader of GCC and her work spans a broad range of research topics related to conservation planning and assessments, with a strong focus on applied conservation challenges in Africa. 